\title{
Community based program to improve firearm storage practices in rural Alaska
}

\author{
A Horn, D C Grossman, W Jones, L R Berger
}

Injury Prevention 2003;9:231-234

See end of article for authors' affiliations

Correspondence to: Dr David Grossman Harborview Injury

Prevention and Research Center, 325 Ninth Ave Box 359960, Seattle, WA 98104, USA;

navajo@u.washington.edu

\begin{abstract}
Objective: To develop and evaluate a pilot program to reduce unauthorized access to firearms by youth by distributing gun safes and trigger locks to households.

Design: Pilot intervention with pre/post-evaluation design.

Setting: Two Alaska Native villages in the Bristol Bay Health Corporation region of southwest Alaska. Subjects: Forty randomly selected households with two or more guns in the home.

Intervention: Initially, a focus group of community members who owned guns was convened to receive input regarding the acceptability of the distribution procedure for the gun storage devices. One gun safe and one trigger lock were distributed to each of the selected households during December 2000. Village public safety officers assisted with the distribution of the safes and provided gun storage education to participants.

Main outcome measures: Baseline data were collected regarding household gun storage conditions at the time of device distribution. Three months after distribution, unannounced onsite home visits were conducted to identify if residents were using the gun safes and/or trigger locks.

Results: All selected households had at least two guns and $28(70 \%)$ of the 40 households owned more than two guns. At baseline, $85 \%$ of homes were found to have unlocked guns in the home and were most often found in the breezeway, bedroom, storage room, or throughout the residence. During the follow up visits, $32(86 \%)$ of the 37 gun safes were found locked with guns inside. In contrast, only $11(30 \%)$ of the 37 trigger locks were found to be in use.

Conclusions: This community based program demonstrated that Alaska Native gun owners accepted and used gun safes when they were installed in their homes, leading to substantial improvements in gun storage practices. Trigger locks were much less likely to be used.
\end{abstract}

$\mathrm{T}$ he rates of suicide in Alaska, particularly among Alaska Natives, are disproportionately high among adolescents and young adults. During 1999-2000, the rate of suicide among 15-19 year old Native males was 173 per 100000 , compared with 13 per 100000 for all youth of the same age in the United States. ${ }^{1}$ Sixty five percent of suicides in this population are completed with a firearm. Firearm injuries lead to more fatalities among children and adolescents in Alaska than any other cause. ${ }^{2}$ Sixty five percent of these deaths are from suicide, $23 \%$ from homicide, with the remainder being unintentional or of undetermined intent. About $60 \%$ of homes report having a firearm in or around the home, according to the 1996 state Behavioral Risk Factor Survey, but the prevalence of firearms in the rural parts of Alaska may be much higher. ${ }^{2}$ Given the high prevalence of firearms and the association with the risk of firearm injury, interventions are need to reduce unauthorized access to guns by children and teenagers. In this pilot program, we sought to improve the storage of guns in two small Alaskan villages by distributing firearm storage devices to selected homes using local public health and law enforcement personnel.

\section{METHODS}

\section{Program design and site}

This was a pilot injury prevention program with a pre/post evaluation design. The study was conducted under the auspices of the Bristol Bay Area Health Corporation in two villages of southwest Alaska. Bristol Bay is a very rural region, with some 6000 residents living in a 40000 square mile area. The population in the area is $70 \%$ Native, $22 \%$ white, and $7 \%$ mixed race.

The two communities were selected for the program based on the following criteria: (a) ease of access from a main hub town; (b) the presence of a village public safety officer (VPSO) employed within the community; and (c) a high incidence of firearm related deaths and injuries. The VPSOs are individuals residing in the village as first responders to public safety emergencies such as search and rescue, fire protection, emergency medical assistance, crime prevention, and basic law enforcement. At the time of the intervention, community A had approximately 500 residents in 95 homes and community $\mathrm{B}$ had approximately 840 residents in 210 homes. The populations of both villages are approximately 95\% Native Alaskan.

\section{Intervention program and preliminary studies}

The long term purpose of this program was to reduce unintentional and intentional firearm deaths and injuries among youth by decreasing access to guns. Two devices, gun safes and trigger locks, were distributed without cost to residents. These devices were chosen for their perceived acceptability and compatibility with rifles, the predominant gun type in the villages. The safes (Homak model 3660) weighed approximately 74 pounds and could hold up to eight long guns and three handguns. Additional side bins were available in the gun safe for storage of ammunition. A key type lock was used to secure the locking mechanism for both the gun safe (also referred to as a "lock box") and trigger lock. Trigger locks (Remington) interfere with the action of the trigger. Most locks consist of two pieces that cover the trigger apparatus from each side. The safes cost approximately $\$ 90$ apiece (excluding shipping), and trigger locks were approximately $\$ 8$.

Several preliminary community meetings were held to gain support for the program. A meeting was conducted with members of the local police, medical and mental health, and administrative staff from the Bristol Bay Area Health 
Corporation to discuss the proposed gun safe and trigger lock distribution program. Another meeting was conducted withVPSOs from several regional communities. The VPSOs learned how to install and distribute the gun safes and what gun storage safety messages to deliver.

A focus group was also conducted with seven gun owners selected by the VPSO in community B. The purpose of the focus group was to discuss the feasibility and acceptability of the proposed distribution process. The results of the focus group indicated that the gun owners were supportive of the program and were willing to accept the presence of a VPSO in the home.

\section{Subject selection}

To participate in the program, a recipient had to be a resident of one of the two villages, at least 18 years of age, a home owner or primary renter, an owner of at least two long guns, and without a gun safe at the time of the distribution. The participants also had to agree to an unannounced, future in-home visit. Participants provided signed, informed consent under procedures approved by the Bristol Bay Area Health Corporation.

Because of limited resources, not all eligible homes could receive devices. The gun safes and trigger locks were distributed to 40 randomly selected homes, 20 in each village. In community $\mathrm{A}$, an aerial photo of the community was available. Numbers were assigned to each house in the photo and a random number generator was used to select numbers. In community B, homes were randomly selected using the 2000 census.

\section{Distribution procedures and data collection}

Each of the 40 selected homes received one gun safe and one trigger lock. One of the authors (AH) and a VPSO jointly distributed the devices. A general script was used to introduce the distribution program. The script noted that the participant was selected randomly, the devices were being provided at no cost, and an evaluation would be conducted in the future by an unannounced visit to inspect the safe and inquire about the trigger lock. A letter from the chief executive officer of the Native health corporation was also given to the participants to demonstrate tribal support for the program. Written material with a gun storage safety message was left with participants. Safes were uncrated, installed, and demonstrated to the household occupants by the VPSO at the time of delivery. The use of a trigger lock was also explained to participants. The VPSO went over the installation directions of the trigger lock and demonstrated the locking mechanism. They also counseled adults to store the device keys in an inaccessible location. Participants were not given guidance regarding which gun should be installed with the lock, nor were any of the homeowners' guns handled during the training. At the time of the distribution, the location of the guns, the locking status of the guns, and whether the guns were loaded or unloaded were noted as reported by the participant. Households were visited again three months after delivery of the safety devices to determine whether the devices were being used, and whether the proportion of guns being stored securely had increased. Visits were unannounced and conducted again by the same author and VPSO. We employed a standardized questionnaire and visual inspection to determine if the gun safe and trigger locks were being used by the gun owners. Rather than conducting an exhaustive search of the household, we relied on self report by the participants to determine if all guns in the household were secured. Careful notation was made about the presence of guns in the home in open view outside of the safe.

This demonstration project was reviewed and approved by the ethics committee of the Bristol Bay Area Health Corporation. The final manuscript was reviewed and approved by the Alaska Area Research and Publications Committee of the Alaska Native Medical Center.

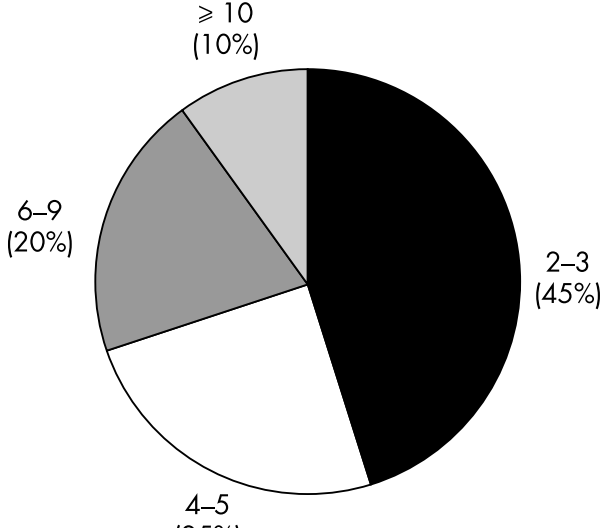

$(25 \%)$

Figure 1 Number of guns per household at baseline.

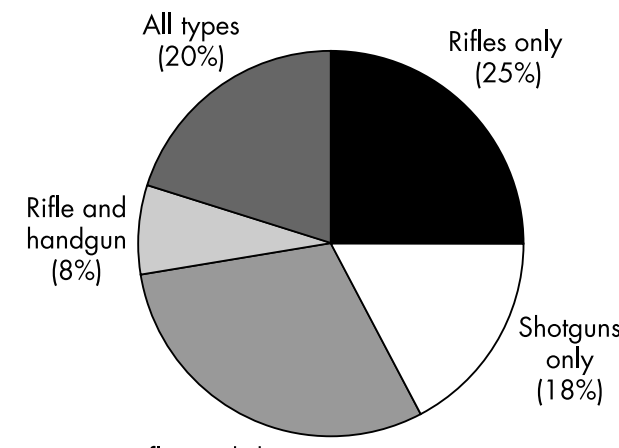

Rifles and shotguns

$(29 \%)$

Figure 2 Guns types found in households at baseline.

\section{RESULTS}

The 40 participating households had an average of five persons per household, with a mean of 2.4 children under the age of 16 in residence. These homes had a mean of 5.2 guns per home. Twenty two (55\%) of the homes had four or more guns (fig 1). The types of guns found in the households are noted in fig 2 . All homes had at least one long gun (rifle or shotgun) and none had only a handgun. Twenty nine $(72 \%)$ of homes had only long guns. At the time of the baseline survey, only six $(15 \%)$ of these guns were locked but 38 (95\%) were not loaded. Ammunition was self reported as locked in only three $(8 \%)$ of these homes. The location of the guns at baseline is noted in table l. Half of participating households stored guns in either the entryway or the bedroom. Approximately one quarter of homes stored them in a storage room or kitchen and another quarter stored them in multiple locations. The storage location of ammunition was most likely to be in multiple locations.

Table 1 Gun and ammunition storage locations in participating households $(n=40)$

\begin{tabular}{lll}
\hline Storage location & $\begin{array}{l}\text { Households' } \\
\text { gun(s) location }\end{array}$ & $\begin{array}{l}\text { Households' } \\
\text { ammunition location }\end{array}$ \\
\hline Entryway & 10 & 8 \\
Bedroom & 10 & 10 \\
Storage room & 8 & 0 \\
Kitchen & 3 & 4 \\
Multiple locations & 9 & 15 \\
Closet/pantry & 0 & 2 \\
Hallway & 0 & 1 \\
\hline
\end{tabular}




\begin{tabular}{|c|c|}
\hline Outcome measure & No (\%) \\
\hline \multicolumn{2}{|l|}{ Gun safe } \\
\hline In use, locked & $32(86)$ \\
\hline In use, unlocked & $3(8)$ \\
\hline Not in use & $2(6)$ \\
\hline \multicolumn{2}{|l|}{ Trigger lock } \\
\hline In use, locked & $11(30)$ \\
\hline Not in use & $26(70)$ \\
\hline
\end{tabular}

Table 3 Participants' reasons for not utilizing trigger locks

\begin{tabular}{ll}
\hline $\begin{array}{l}\text { Main reason for not using } \\
\text { trigger lock }\end{array}$ & No (\%) \\
\hline Inconvenient & $7(27)$ \\
Hasn't had a chance to try it & $3(12)$ \\
Not sure how to use & $2(8)$ \\
No pistol for trigger lock & $1(4)$ \\
Don't like for long guns & $1(4)$ \\
Only use when travel & $1(4)$ \\
Not sure/don't know & $7(27)$ \\
No response & $4(15)$ \\
\hline
\end{tabular}

\begin{tabular}{llllll} 
Table 4 & \multicolumn{4}{l}{ Device used by total number of guns owned } \\
\hline & $\begin{array}{l}\text { Safe and } \\
\text { trigger } \\
\text { lock used }\end{array}$ & $\begin{array}{l}\text { Only } \\
\text { trigger } \\
\text { lock used }\end{array}$ & $\begin{array}{l}\text { Only } \\
\text { safe used }\end{array}$ & $\begin{array}{l}\text { No } \\
\text { device } \\
\text { used }\end{array}$ & $\begin{array}{l}\text { Safe used } \\
\text { unlocked }\end{array}$ \\
\hline$>5$ guns & 5 & 0 & 5 & 1 & 1 \\
$\leqslant 5$ guns & 6 & 0 & 16 & 1 & 2 \\
Total & 11 & 0 & 21 & 2 & 3 \\
\hline
\end{tabular}

A follow up visit at three months after baseline was accomplished with the residents of 37 (93\%) of the original 40 homes (table 2 ). We found that $32(86 \%)$ of the 37 gun safes had guns stored in the locked safe. Two participants were not storing guns in the gun safes and three safes had handguns stored in the them but were unlocked. Twenty five (78\%) of the 37 participants reported that all guns were now secure in the household with a gun safe or with a gun safe and trigger lock combination.

Only $11(30 \%)$ of the 37 trigger locks that were distributed were being used. Reasons given by persons for not using the locks are indicated in table 3 . The most common reason for not using the trigger lock was that it was "inconvenient". None of the households used trigger locks alone without also storing the gun in the safe. Households with more than five guns $(n=12)$ appeared to be somewhat more likely than households with five or fewer guns $(n=25)$ to use both devices $(27 \%$ $v 50 \%, \mathrm{p}=0.24)$, though this difference was not statistically significant (table 4 ).

\section{DISCUSSION}

This gun safe distribution program led to positive changes in gun storage in these remote villages of rural Alaska. There have been only a few other studies of community based firearm storage campaigns. ${ }^{3}$ To our knowledge, this is the first published report in which gun devices were distributed and installed in homes with the collaboration of law enforcement officers. That such a high proportion $(86 \%)$ of gun owners

\section{Key points}

- Suicide rates among young Alaska Native males age 15-19 years are over 10-fold higher than rates among youth of the same age in the US.

- At least $60 \%$ of homes in Alaska have firearms in the home.

- Before the intervention program, $15 \%$ of firearms in the home were locked.

- Following the distribution of gun safes to village households, $86 \%$ of gun safes were locked with guns inside. $78 \%$ of respondents reported all guns were locked in the household.

were utilizing the gun safes is likely due to several factors. Gun owners are more likely to secure firearms when children are present in the household. ${ }^{4}$ In this project, $83 \%$ of households included children under 17 years of age. Firearms are also more likely to be unlocked when they are used for personal protection. Most of these homes keep guns for other purposes, such as recreation or subsistence hunting. ${ }^{5}$

Trigger locks were not as well received; $70 \%$ of them were not being used. One possible reason might be that it was easier for participants to keep all their guns in the gun safe than attach and disconnect trigger locks before use of a firearm. Since we provided only one trigger lock and each home had at least two guns, the safe provided a consistent method to store all the household's guns.

Guns used in adolescent suicide most often come from the child's home. ${ }^{6}$ By raising the proportion of locked guns from $15 \%$ to $85 \%$, the gun safe program promises to be a potentially effective approach to reducing suicides and unintentional injuries in the villages of the Bristol Bay Area Health Corporation. However, this study was not designed to determine the effectiveness of this method, and thus the sample size of this pilot program (40 households) did not have sufficient statistical power to detect differences in the incidence of firearm injuries. Even in the absence of statistical power, however, our demonstration program has already had an impact on gun safety.

Since our study was completed, one village council voted to finance the purchase of gun safes for residents who did not receive a gun safe through our pilot distribution program and several other Alaska communities have launched lock box distribution programs. As improved gun storage practices are more widely adopted, regional rates of firearm injuries may be likely to fall.

\section{ACKNOWLEDGEMENTS}

The authors wish to acknowledge the important help and advice received by Michael Keiffer and the Alaska Native Tribal Health Consortium program; Stanley Active Jr, Evon Wonhola, Calvin Fletcher, and Brad Angasan.

This project was supported with funding from the Bristol Bay Area Health Corporation and the Centers for Disease Control and Prevention ((R49/CCR002570-17).

The opinions expressed in this paper are those of the author and do not necessarily reflect the views of the IHS.

Authors' affiliations

A Horn, Indian Health Service, Reno, Nevada

D C Grossman, Harborview Injury Prevention and Research Center and Department of Pediatrics, University of Washington, Seattle W Jones, Injury Prevention Program, Bristol Bay Area Health Corporation, Dillingham, Alaska

L R Berger, Albuquerque, New Mexico

\section{REFERENCES}

1 Centers for Disease Control and Prevention. Web-based Injury Statistics Query and Reporting System (WISQARS). [Online.] National 
Center for Injury Prevention and Control, Centers for Disease Control and Prevention (producer), 2001. Available from: www.cdc.gov/ncipc/ wisqars (accessed November 2002)

2 Johnson MS, Moore M, Mitchell P, et al. Serious and fatal firearm injuries among children and adolescents in Alaska: 1991-1997. Alaska Med 2000;42:3-10, 27

3 Coyne-Beasley T, Schoenbach VJ, Johnson RM. “Love our kids, lock your guns": a community-based firearm safety counseling and gun lock distribution program. Arch Pediatr Adolesc Med 2001;155:659-64.
4 Stennies G, Ikeda R, Leadbetter $S$, et al. Firearm storage practices and children in the home, United States, 1994. Arch Pediatr Adolesc Med $1999 ; 153: 586-90$

5 Weil DS, Hemenway D. Loaded guns in the home. Analysis of a national random survey of gun owners. JAMA 1992;267:3033-7.

6 Grossman DC, Reay DT, Baker SA. Self-inflicted and unintentional firearm injuries among children and adolescents: the source of the firearm. Arch Pediatr Adolesc Med 1999;153:875-8.

\section{BOARD MEMBER BIOGRAPHY}

\section{Etienne Krug, MD, MPH}

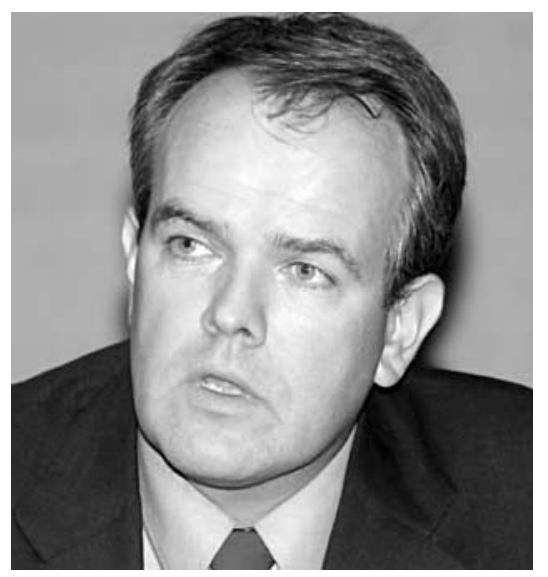

Krug was appointed Director of the Department for Violence and Injury Prevention at the World Health Organization in Geneva, Switzerland in October 2000. He has coordinated the development of WHO's first World Report on Violence and Health published in 2002 and oversees preparations for World Health Day 2004, dedicated to road safety. He also chairs the International Organizing Committee for World Conferences on Injury Prevention and Safety Promotion.

From July 1995 to December 1999 Dr Krug was a medical epidemiologist in the Division of Violence Prevention at the US Centers for Disease Control and Prevention in Atlanta. During that time he designed, conducted, and published epidemiological research focusing on violence prevention at the national and international level.

Between 1987 and 1995, Dr Krug worked in war-torn countries for several humanitarian organizations. He served as a doctor in Mozambique and country director in Nicaragua and E Salvador for Médecins sans Frontières, as a health and nutrition coordinator for the United Nations High Commissioner for Refugees during the Rwandan genocide, and as a human rights observer in Haiti.

Dr Krug holds a degree in medicine from the University of Louvain in Brussels, Belgium and a masters degree in public health from Harvard University. He has earned several awards including the 1998 Alexander D Langmuir and the Paul C Schnitker Awards from the Centers for Disease Control and Prevention and the Rosalie Wolf Memorial Elderly Abuse Prevention Award. Dr Krug is editor of several scientific journals and has published many original articles, editorials, and chapters. He is fluent in French, English, Dutch, Spanish, and Portuguese. 